\title{
Chronic Disease Disparities by County Economic Status and Metropolitan Classification, Behavioral Risk Factor Surveillance System, 2013
}

\author{
Kate M. Shaw, PhD; Kristina A. Theis, PhD; Shannon Self-Brown, PhD; \\ Douglas W. Roblin, PhD; Lawrence Barker, PhD
}

\begin{abstract}
Suggested citation for this article: Shaw KM, Theis KA, SelfBrown S, Roblin DW, Barker L. Chronic Disease Disparities by County Economic Status and Metropolitan Classification, Behavioral Risk Factor Surveillance System, 2013. Prev Chronic Dis 2016;13:160088. DOI: http://dx.doi.org/10.5888/ pcd13.160088.
\end{abstract}

\section{PEER REVIEWED}

\section{Abstract}

\section{Introduction}

Racial/ethnic disparities have been studied extensively. However, the combined influence of geographic location and economic status on specific health outcomes is less well studied. This study's objective was to examine 1) the disparity in chronic disease prevalence in the United States by county economic status and metropolitan classification and 2) the social gradient by economic status. The association of hypertension, arthritis, and poor health with county economic status was also explored.

\section{Methods}

We used 2013 Behavioral Risk Factor Surveillance System data. County economic status was categorized by using data on unemployment, poverty, and per capita market income. While controlling for sociodemographics and other covariates, we used multivariable logistic regression to evaluate the relationship between economic status and hypertension, arthritis, and self-rated health.

\section{Results}

Prevalence of hypertension, arthritis, and poor health in the poorest counties was $9 \%, 13 \%$, and $15 \%$ higher, respectively, than in the most affluent counties. After we controlled for covariates, poor counties still had a higher prevalence of the studied conditions.

\section{Conclusion}

We found that residents of poor counties had a higher prevalence of poor health outcomes than affluent counties, even after we controlled for known risk factors. Further, the prevalence of poor health outcomes decreased as county economics improved. Findings suggest that poor counties would benefit from targeted public health interventions, better access to health care services, and improved food and built environments.

\section{Introduction}

Chronic diseases affect 117 million American adults, with almost 60 million having more than one chronic condition (1). However, the burden of chronic disease is not shared equally. Although racial/ethnic disparities are well known, the combined influence of geographic and economic status on specific health outcomes is less well studied (2). A close examination of the relationship between economic indicators and health conditions might provide important information and insight into the intervention type best suited for particular groups.

Despite many advances in public health (3), much remains to be done in prevention and control of morbidity and mortality, particularly chronic conditions (2). As demonstrated in countries at all income levels, poor health outcomes increase as socioeconomic position decreases (referred to as the "social gradient": ie, inequalities in health status are related to inequalities in social status) (4).

Socioeconomics can be measured by using individual characteristics (eg, education or household income) or community characteristics (eg, percentage of residents living in poverty). Social determinants can drive gradient-related health outcomes, and these 
can be further categorized as downstream (more proximal to the individual) or upstream (more distal from the individual) (5). The most distal social determinants are socioeconomic opportunities and resources, which affect living and working environments. The most downstream determinants that directly affect an individual's health are behaviors and level of access to medical care.

In the United States, economic opportunities and resources, as measured by an area's poverty level, are associated with mortality. Galea and colleagues estimated that more than 39,000 deaths in 2000 were attributed to area-level poverty (6).

Here, we examine 1) the prevalence of selected chronic diseases by US county economic status and by metropolitan classification and 2) the social gradient by county economic status, both overall and by metropolitan classification. We use multivariable logistic regression to examine the association between county economic status and prevalence of hypertension, arthritis, and poor health, after controlling for risk factors.

\section{Methods}

Data from the 2013 Behavioral Risk Factor Surveillance System (BRFSS) were analyzed. The BRFSS is a random-digit-dialed survey of noninstitutionalized civilian adults 18 years or older in the United States (7). To account for probability of selection and population distribution, the BRFSS uses a complex sample survey design and weighting. Survey data from both landline and cellphone-only households were used.

Respondents were asked questions related to their health, risky behaviors, and use of health services. They were asked whether a health professional ever told them they have specific chronic diseases and whether they have self-reported risk factors. We examined data on leisure-time physical activity, poor health, body mass index classified as overweight or obese, hypertension, high cholesterol, heart disease, arthritis, diabetes, current cigarette smoking, depressive disorder, asthma, and chronic obstructive pulmonary disease. Respondents were also asked to rate their general health as excellent, very good, good, fair, or poor; they were considered to have poor health if they answered that their health was fair or poor. We considered data as missing if respondents said that they did not know whether they had the condition, were not sure whether they had the condition, or refused to answer the question about the condition; we excluded missing data from analyses. The full survey questionnaire is available (8).

To measure county economic status, we used an index similar to the one the Appalachian Regional Commission (ARC) used for that purpose for many years. This method uses an index measure to assess economic distress in Appalachian counties (9). Three economic measures were used to create county economic status: 2013 unemployment rate, 2013 per capita market income, and 5year (2009-2013) poverty rates. Unemployment estimates are provided by the US Bureau of Labor Statistics (10), data on per capita market income are from the US Bureau of Economic Analysis (11), and data on poverty level are from the US Census Bureau's American Community Survey (12). For simplicity, we used only 1 year of unemployment data instead of the 3 years used by ARC; adding 2 additional years of data had little impact. An index variable was created by adding together the standardized values of each of these economic measures. The negative standardized values for unemployment and poverty were used to make smaller values more desirable. The summed values were categorized as quintiles. These quintiles were labeled poorest, poor, median, affluent, and most affluent.

County metropolitan classification was determined by using the US Office of Management and Budget's metropolitan classifications: regions with at least 1 urbanized area of 50,000 or greater population and their socially and economically integrated adjacent areas were considered to be metropolitan (13). Because of data limitations, independent cities in Virginia (ie, cities not in the territory of any county) with populations of less than 100,000 were combined with their adjacent county; 10 independent cities had 100,000 or greater population and had economic measures available, so they were included as separate geographic regions in our analyses. Because Alaska and Hawaii have unique economies, analyses were limited to the contiguous United States, resulting in a total of 3,070 counties and 10 independent cities in Virginia (3,080 geographic regions in all). For convenience, we refer to all geographic regions (counties and independent cities) as "counties." We also determined the economic status of each county and compared the metropolitan counties $(1,939 ; 63.0 \%)$ with the nonmetropolitan counties $(1,141 ; 37.0 \%)$.

Several risk factors are associated with chronic disease, including not having health insurance, being obese, using tobacco, and not participating in physical activity (14). Participants were considered to have health insurance if they responded that they had any health care coverage at the time of the survey. Overweight or obese was defined as having self-reported height and weight measurements equivalent to a body mass index of $25.0 \mathrm{~kg} / \mathrm{m}^{2}$ or higher. Respondents who smoked at least 100 cigarettes in their lifetime and stated that they still smoke were considered current smokers. Respondents were considered physically active if they participated in any leisure-time physical activities during the previous month.

County of residence was not available for 22,639 (4.8\%) respondents, so data on those respondents were excluded. The final analytic sample consisted of 448,790 respondents in 3,064 counties and

\footnotetext{
The opinions expressed by authors contributing to this journal do not necessarily reflect the opinions of the U.S. Department of Health and Human Services, the Public Health Service, the Centers for Disease Control and Prevention, or the authors' affiliated institutions.
} 
10 Virginia cities (3,074 counties). Analyses were conducted using SAS (version 9.3) callable SUDAAN, release 11.0.1 (15), to account for the complex survey design. We used multivariable logistic regression to examine the relationship between county economic status and hypertension, arthritis, and self-rated health status after controlling for sociodemographic and health risk factors (age, sex, race/ethnicity, education, household income, inadequate or no health insurance, overweight or obesity, current cigarette smoking, lack of physical activity), and metropolitan county classification. Weighted percentages, adjusted prevalence ratios, and their $95 \%$ confidence intervals were calculated. To assess disparities among economic groups, the estimate for the group of poorest counties was subtracted from that for the most affluent group of counties. Confidence intervals for the differences that do not include zero indicate a significant difference at the 2sided $\alpha$ of .05. Estimates were calculated overall and for metropolitan and nonmetropolitan counties separately. Adjusted prevalence ratios were calculated using SUDAAN's logistic procedure and the predicted marginal statement with the adjusted risk ratios option (15).

\section{Results}

Demographic characteristics differed by metropolitan classification (Table 1). Most respondents lived in metropolitan counties (weighted percentage, 83.5\%). Compared with nonmetropolitan residents, those living in metropolitan counties were more likely to be aged 18 to 44 years, Hispanic or non-Hispanic black, and a college graduate; they were also more likely to have household incomes of $\$ 75,000$ or higher. In contrast, nonmetropolitan respondents were more likely to be aged 65 years or older, be non-Hispanic white, have less than a college education, and have a household income of less than $\$ 75,000$.

We found differences in chronic disease and risk factors by economic status (Table 1). Large percentage-point differences between the most affluent and poorest counties were in 3 health outcomes and 3 risk factors: poor health $(-11.7)$, hypertension $(-8.7)$, arthritis $(-7.0)$, body mass index classified as overweight or obese (-9.9), no leisure-time physical activity (-9.4), and current smoking (-7.8). All these differences were significant, with the poorest counties having the worst outcomes.

Estimates of chronic disease and risk factors also differed by metropolitan classification. Respondents in nonmetropolitan counties were significantly more likely to report chronic diseases (excluding asthma) and risk factors than were those in metropolitan counties. Differences between the most affluent and the poorest counties also varied by metropolitan classification. The largest percentage-point differences between metropolitan and nonmetro- politan counties were found for hypertension (metropolitan, -6.2 ; nonmetropolitan, -10.1), poor health (metropolitan, -9.4; nonmetropolitan, -12.1), arthritis (metropolitan, -5.2 ; nonmetropolitan, -6.8), current smoking (metropolitan, -5.8 ; nonmetropolitan, -7.4 ), and body mass index classified as overweight or obese (metropolitan, -7.8; nonmetropolitan, -6.8).

Hypertension was the disease for which the differences in estimates for each economic county group by metropolitan classification were largest. The prevalence of hypertension declined as economic county group improved for both metropolitan and nonmetropolitan counties; however, the difference was greater for nonmetropolitan counties (Figure). At every level of county economic status, metropolitan counties had a lower prevalence of hypertension than did nonmetropolitan counties.

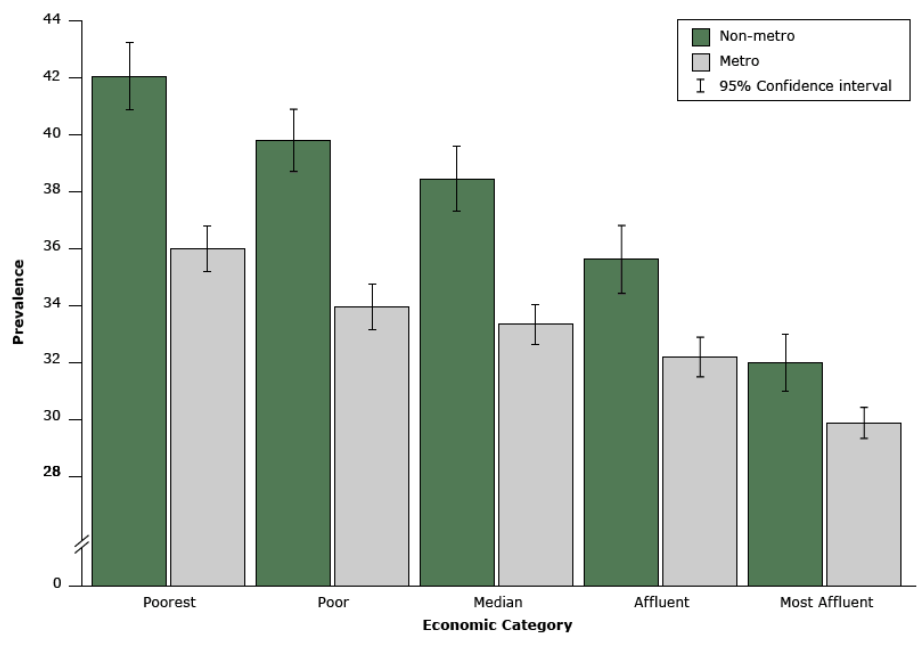

Figure. Prevalence (weighted estimates and 95\% Cls) of hypertension by county metropolitan classification and economic category, adults ( $\geq 18 \mathrm{y})$, Behavioral Risk Factor Surveillance System, 2013. Hypertension was defined by self-report of ever having been told by a health professional that they had hypertension. Metropolitan and nonmetropolitan categories were determined by using the Office of Management and Budget's February 2013 delineations and data from the U.S. Census Bureau, Population Division (http:// www.census.gov/population/metro/). County economic status was determined by using 2013 unemployment rate, per capita market income, and poverty rate for each county. An index was used to order counties into quintiles (poorest, poor, median, affluent, and most affluent). Abbreviations: $\mathrm{Cl}$, confidence interval; metro, metropolitan; nonmetro, nonmetropolitan.

The prevalence of hypertension, arthritis, and poor health was lower in more affluent counties than in poor counties, and nonmetropolitan counties had higher rates than did metropolitan counties (Table 2). The prevalence of these conditions was higher or highest among those in the older age groups. Men reported hypertension more often than women, whereas women had higher rates of arthritis and poor health. Overall, among the 4 racial/ethnic groups studied, the highest prevalence of hypertension $(42.8 \%)$

The opinions expressed by authors contributing to this journal do not necessarily reflect the opinions of the U.S. Department of Health and Human Services, the Public Health Service, the Centers for Disease Control and Prevention, or the authors' affiliated institutions. 
was among non-Hispanic blacks, the highest prevalence of arthritis $(29.6 \%)$ was among non-Hispanic whites, and the highest prevalence of poor health $(26.0 \%)$ was among Hispanics. The prevalence of each condition had an inverse linear relationship with education and household income (ie, the prevalence of each condition was lowest for those with the highest levels of education and income). The prevalence of hypertension and arthritis was higher among respondents with health insurance than among those without health insurance; those without health insurance had higher prevalence of poor health than those with health insurance. Hypertension, arthritis, and poor health were reported more often by respondents who were overweight or obese and by those who did not participate in physical activity. Current smokers reported arthritis and poor health more often than did nonsmokers, but hypertension prevalence did not significantly differ by smoking status.

After we adjusted for covariates, an association between county economic status and hypertension, arthritis, and poor health remained (Table 3). The prevalence of hypertension in the poorest counties was $9 \%$ higher than in the most affluent counties (adjusted prevalence ratio, $1.09 ; 95 \% \mathrm{CI}, 1.05-1.12$ ). For arthritis, the poorest counties had $13 \%$ higher prevalence than the most affluent counties (adjusted prevalence ratio, 1.13; 95\% CI, 1.09-1.18). The greatest difference in prevalence rates among the 3 conditions was found for poor health, with the poorest counties having $15 \%$ higher prevalence than the most affluent counties (adjusted prevalence ratio, 1.15 ; $95 \% \mathrm{CI}, 1.10-1.21$ ).

\section{Discussion}

We examined the association between county economic status and prevalence of chronic disease and associated risk factors. For hypertension, arthritis, and poor health, the prevalence was lower as county economics improved. This association remained after we adjusted for covariates. To our knowledge, this is the first study to examine national prevalence of chronic disease based on county economics using a rigorous economic index.

Our results are consistent with those of previous research on socioeconomic status and health outcomes. Increased mortality and poor health is associated with area-level poverty even after the data are adjusted for individual risk factors $(16,17)$. Research also shows an increase in heart disease among residents in disadvantaged neighborhoods (18). Limited research has been conducted on arthritis and area-level poverty in the United States, although a North Carolina study showed an interaction effect between community poverty and low individual socioeconomic status (19).

Several characteristics related to the gradient in health and economic status are potentially modifiable. These include access to health care, dissemination of evidence-based community-de- livered public health interventions, and environmental barriers to healthy food and physical activity. Residents of poor counties might have more barriers to accessing health care services than those in affluent counties. Increased access to services, such as Medicaid, is likely to benefit poor counties the most, since more residents in these counties than in affluent counties would qualify for these services.

Our findings also suggest that the higher prevalence of hypertension, arthritis, and poor health in nonaffluent counties makes these areas a prime target for clinical-community linkages in the form of greater dissemination of evidence-based, community-delivered, self-management education and physical activity programs. For example, a recent meta-analysis of the Chronic Disease Self-Management Program showed that this program can generate sustained (9-12 months) improvements in several measures of psychological health (eg, depression, health distress, self-efficacy), aerobic exercise, and cognitive symptom management and at least 4-to-6-month improvements in energy, fatigue, and self-rated health (20). The benefits of evidence-based public health interventions suggest that these programs may be especially meaningful and important components in a comprehensive strategy to improve health outcomes and in the primary and tertiary prevention of chronic disease in economically disadvantaged US counties.

The food environment in poor counties may also contribute to their higher prevalence of chronic diseases. Density of fast-food restaurants and convenience stores tends to be higher in poor neighborhoods than in affluent neighborhoods (21). The number of fast-food restaurants and convenience stores is positively associated with mortality and diabetes (22). Methods for bringing healthy food into poor counties include neighborhood farmers markets, community-supported agriculture, cooperative grocery stores, community gardens, and mobile stores (23). Interventions aimed at increasing access to healthy food might improve the health of residents in poor counties.

A third factor that might affect chronic disease prevalence in poor counties is the physical environment. Neighborhoods with low socioeconomic status are less likely to have access to parks and recreation facilities or to have an environment that supports active transportation (eg, walking or biking to work), less likely to be close to commercial areas, schools, and work, and less likely to have safe walkable routes (24) to any place. Establishing programs and implementing policies that promote safe routes to school and work and community bicycling increase active transportation (25). Improving built-environment characteristics is associated with increased physical activity and could improve the health of residents in poor counties.

The opinions expressed by authors contributing to this journal do not necessarily reflect the opinions of the U.S. Department of Health and Human Services, the Public Health Service, the Centers for Disease Control and Prevention, or the authors' affiliated institutions. 
This study has several limitations. First, BRFSS data are subject to nonreporting and social desirability bias. Second, biases might differ by geographic location, as was found for obesity (26). Third, interviews were limited to respondents living in noninstitutionalized settings, which excludes residents of skilled nursing facilities and retirement homes, and might result in an underestimation of the chronic disease burden. Finally, county of residence was determined according to the current residence of the respondent, which did not account for previous places of residence.

Our study also has important strengths. We extend the literature on associations between local economic activity for 2 important chronic conditions, hypertension and arthritis, and one important representation of health status, self-rated health. Hypertension and arthritis are 2 of the most common chronic conditions affecting US adults (27). Additionally, self-rated health is a robust global measure of health and has associations with morbidity and mortality $(28,29)$; self-rated health is also sensitive to changes in neighborhood and individual-level social capital (30). By establishing a relationship between hypertension, arthritis, and poor health with county-level economics, we identified meaningful target groups by condition and by geographic area in which gains in public health might occur with appropriate intervention. Other strengths of our study include using a population-based data source with sufficient sample size to find small to modest adjusted associations and using an accepted (used by ARC) economic index with enough levels to illustrate meaningful variability at the county level.

Residents in poor counties have a greater prevalence of hypertension, arthritis, and poor health than residents in affluent counties. Furthermore, while a social gradient exists, with increases in poor health outcomes as county-level economic status decreases, we have explicitly documented this association for 2 highly prevalent chronic conditions and poor self-rated health for virtually all counties in the contiguous United States. Improvements to food and built environments and access to health care services and evidence-based, community-delivered public health interventions in counties with an economic status below that of the most affluent might help decrease the prevalence and impact of chronic disease overall and decrease the disparities seen in poor counties.

\section{Author Information}

Corresponding Author: Kate M. Shaw, PhD, Division of Global Migration and Quarantine, Centers for Disease Control and Prevention, 1600 Clifton Rd, MS E28, Chamblee, GA 303294027. Telephone: 404-498-0789. Email: kmshaw@cdc.gov.
Author Affiliations: Kristina A. Theis, Lawrence Barker, Centers for Disease Control and Prevention, Atlanta, Georgia; Shannon Self-Brown, Douglas Roblin, Georgia State University School of Public Health, Atlanta, Georgia. Dr Shaw is also affiliated with Georgia State University School of Public Health, Atlanta, Georgia.

\section{References}

1. Ward BW, Schiller JS, Goodman RA. Multiple chronic conditions among US adults: a 2012 update. Prev Chronic Dis 2014;11:E62.

2. Centers for Disease Control and Prevention. CDC health disparities and inequalities report — United States, 2011. MMWR Suppl 2011;60(1):1-113.

3. Centers for Disease Control and Prevention (CDC). Ten great public health achievements - United States, 1900-1999. MMWR Morb Mortal Wkly Rep 1999;48(12):241-3.

4. Marmot M, Friel S, Bell R, Houweling TAJ, Taylor S; Commission on Social Determinants of Health. Closing the gap in a generation: health equity through action on the social determinants of health. Lancet 2008;372(9650):1661-9.

5. Robert Wood Johnson Foundation. Overcoming obstacles to health. 2008. http://www.rwjf.org/content/dam/farm/reports/ reports/2008/rwjf22441. Accessed June 17, 2016.

6. Galea S, Tracy M, Hoggatt KJ, Dimaggio C, Karpati A. Estimated deaths attributable to social factors in the United States. Am J Public Health 2011;101(8):1456-65.

7. Xu F, Town M, Balluz LS, Bartoli WP, Murphy W, Chowdhury PP, et al. Surveillance for certain health behaviors among States and selected local areas — United States, 2010. MMWR Surveill Summ 2013;62(1,SS-1):1-247.

8. Centers for Disease Control and Prevention. BRFSS questionnaires. http://www.cdc.gov/brfss/questionnaires.htm. Accessed June 17, 2016.

9. Appalachian Regional Commission. Distressed designation and county economic status classification system, FY $2007-F Y 2016$. http://www.arc.gov/research/ SourceandMethodologyCountyEconomicStatusFY2007FY201 6.asp. Accessed June 17, 2016.

10. US Bureau of Labor Statistics. Local area unemployment statistics: county data. http://www.bls.gov/lau/ home.htm\#cntyaa. Accessed June 17, 2016.

11. US Bureau of Economic Analysis. Regional economic accounts: local area personal income. http://bea.gov/regional/. Accessed June 17, 2016.

12. US Census Bureau. American Community Survey. http:// www.census.gov/acs/www/. Accessed June 17, 2016.

The opinions expressed by authors contributing to this journal do not necessarily reflect the opinions of the U.S. Department of Health and Human Services, the Public Health Service, the Centers for Disease Control and Prevention, or the authors' affiliated institutions. 
13. US Office of Management and Budget. Revised delineations of metropolitan statistical areas, micropolitan statistical areas, and combined statistical areas, and guidance on uses of the delineations of these areas. 2013. http://www.whitehouse.gov/ sites/default/files/omb/bulletins/2013/b13-01.pdf. Accessed June 17, 2016.

14. Bauer UE, Briss PA, Goodman RA, Bowman BA. Prevention of chronic disease in the 21 st century: elimination of the leading preventable causes of premature death and disability in the USA. Lancet 2014;384(9937):45-52.

15. Research Triangle Institute. SUDAAN language manual, volumes 1 and 2, release 11 . Research Triangle Park (NC): RTI; 2012.

16. LeClere FB, Soobader MJ. The effect of income inequality on the health of selected US demographic groups. Am J Public Health 2000;90(12):1892-7.

17. McLaughlin DK, Stokes CS. Income inequality and mortality in US counties: does minority racial concentration matter? Am J Public Health 2002;92(1):99-104.

18. Diez Roux AV, Merkin SS, Arnett D, Chambless L, Massing M, Nieto FJ, et al. Neighborhood of residence and incidence of coronary heart disease. N Engl J Med 2001;345(2):99-106.

19. Callahan LF, Shreffler J, Mielenz T, Schoster B, Kaufman JS, Xiao $\mathrm{C}$, et al. Arthritis in the family practice setting: associations with education and community poverty. Arthritis Rheum 2008;59(7):1002-8.

20. Brady TJ, Murphy L, O’Colmain BJ, Beauchesne D, Daniels B, Greenberg M, et al. A meta-analysis of health status, health behaviors, and healthcare utilization outcomes of the Chronic Disease Self-Management Program. Prev Chronic Dis 2013; 10:120112.

21. Hilmers A, Hilmers DC, Dave J. Neighborhood disparities in access to healthy foods and their effects on environmental justice. Am J Public Health 2012;102(9):1644-54.

22. Ahern M, Brown C, Dukas S. A national study of the association between food environments and county-level health outcomes. J Rural Health 2011;27(4):367-79.

23. Levy J. 10 ways to get healthy, local foods into low-income neighborhoods: a Minneapolis resource guide. 2007. http:// www.iatp.org/files/258_2_97319.pdf. Accessed June 17, 2016.

24. Sallis JF, Floyd MF, Rodríguez DA, Saelens BE. Role of built environments in physical activity, obesity, and cardiovascular disease. Circulation 2012;125(5):729-37.

25. TenBrink DS, McMunn R, Panken S. Project U-Turn: increasing active transportation in Jackson, Michigan. Am J Prev Med 2009;37(6,Suppl 2):S329-35.

26. Le A, Judd SE, Allison DB, Oza-Frank R, Affuso O, Safford $\mathrm{MM}$, et al. The geographic distribution of obesity in the US and the potential regional differences in misreporting of obesity. Obesity (Silver Spring) 2014;22(1):300-6.
27. Ward BW, Schiller JS. Prevalence of multiple chronic conditions among US adults: estimates from the National Health Interview Survey, 2010. Prev Chronic Dis 2013; 10:E65.

28. Latham K, Peek CW. Self-rated health and morbidity onset among late midlife U.S. adults. J Gerontol B Psychol Sci Soc Sci 2013;68(1):107-16.

29. DeSalvo KB, Bloser N, Reynolds K, He J, Muntner P. Mortality prediction with a single general self-rated health question. A meta-analysis. J Gen Intern Med 2006; 21(3):267-75.

30. Waverijn G, Wolfe MK, Mohnen S, Rijken M, Spreeuwenberg P, Groenewegen P. A prospective analysis of the effect of neighbourhood and individual social capital on changes in selfrated health of people with chronic illness. BMC Public Health 2014;14(1):675.

\footnotetext{
The opinions expressed by authors contributing to this journal do not necessarily reflect the opinions of the U.S. Department of Health and Human Services, the Public Health Service, the Centers for Disease Control and Prevention, or the authors' affiliated institutions.
} 


\section{Tables}

Table 1. Prevalence of Chronic Disease and Risk Factors by County Metropolitan Classification ${ }^{a}$ and Differences Between Most Affluent and Poorest Counties ${ }^{b}$, Adults ( $\geq 18 \mathrm{y}$ ), Behavioral Risk Factor Surveillance System, $2013^{\mathrm{C}}$

\begin{tabular}{|c|c|c|c|c|c|c|}
\hline Characteristic & Overall, \% (95\% Cl) ${ }^{d}$ & $\begin{array}{l}\text { Overall Difference } \\
\text { Between Most } \\
\text { Affluent and } \\
\text { Poorest, Percentage } \\
\text { Points }(95 \% \mathrm{Cl})^{\mathrm{S}}\end{array}$ & Metro, \% $(95 \% \mathrm{Cl})^{d}$ & $\begin{array}{l}\text { Metro Difference } \\
\text { Between Most } \\
\text { Affluent and } \\
\text { Poorest, Percentage } \\
\text { Points }(95 \% \mathrm{Cl})^{\mathrm{d}}\end{array}$ & $\begin{array}{l}\text { Nonmetro, } \%(95 \% \\
\text { Cl) }\end{array}$ & $\begin{array}{l}\text { Nonmetro } \\
\text { Difference Between } \\
\text { Most Affluent and } \\
\text { Poorest, Percentage } \\
\text { Points }(95 \% \mathrm{Cl})^{\mathrm{P}}\end{array}$ \\
\hline No. of respondents (\%) & $448,790^{e}(100)^{d}$ & - & $306,648^{e}(83.5)^{d}$ & - & $142,142^{e}(16.5)^{d}$ & - \\
\hline \multicolumn{7}{|l|}{ Age, y } \\
\hline $18-44$ & 44.7 (44.4 to 45.1$)$ & $-0.8(-1.9$ to 0.3$)$ & 45.5 (45.2 to 45.9 ) & $-1.5(-2.6$ to -0.4$)$ & $40.8(40.2$ to 41.4$)$ & $-2.4(-4.1$ to -0.6$)$ \\
\hline $45-64$ & 35.6 (35.3 to 35.9) & $1.7(0.7$ to 2.7$)$ & 35.5 (35.2 to 35.8$)$ & 2.2 (1.1 to 3.2 ) & 36.3 (35.8 to 36.8 ) & $1.4(-0.2$ to 2.9$)$ \\
\hline$\geq 65$ & $19.6(19.4$ to 19.8$)$ & $-0.9(-1.6$ to -0.2$)$ & $19.0(18.8$ to 19.2$)$ & $-0.7(-1.4$ to 0.1$)$ & 22.9 (22.5 to 23.3$)$ & $1.0(-0.2$ to 2.2$)$ \\
\hline \multicolumn{7}{|l|}{ Sex } \\
\hline Male & 48.2 (47.9 to 48.5$)$ & $1.1(-0.1$ to 2.2$)$ & 48.0 (47.7 to 48.4$)$ & 1.0 (-0.1 to 2.2$)$ & 48.8 (48.3 to 49.4$)$ & 2.9 (1.2 to 4.6$)$ \\
\hline Female & 51.8 (51.5 to 52.2$)$ & $-1.1(-2.2$ to 0.1$)$ & 52.0 (51.6 to 52.3$)$ & $-1.0(-2.2$ to 0.1$)$ & $51.2(50.6$ to 51.8$)$ & $-2.9(-4.6$ to -1.2$)$ \\
\hline \multicolumn{7}{|l|}{ Race/ethnicity } \\
\hline Hispanic & 15.1 (14.9 to 15.4$)$ & $-8.1(-9.2$ to -7.1$)$ & 16.8 (16.5 to 17.2$)$ & $\begin{array}{r}-12.2(-13.2 \text { to } \\
-11.1)\end{array}$ & $6.6(6.2$ to 6.9$)$ & $-0.6(-1.9$ to 0.7$)$ \\
\hline White, non-Hispanic & 66.1 (65.7 to 66.4$)$ & 15.1 (14.0 to 16.3 ) & 63.0 (62.6 to 63.3$)$ & $18.2(17.0$ to 19.3$)$ & $81.6(81.1$ to 82.1$)$ & 20.8 (19.1 to 22.5 ) \\
\hline Black, non-Hispanic & 11.9 (11.7 to 12.1$)$ & $\begin{array}{r}-11.4(-12.3 \text { to } \\
-10.6)\end{array}$ & 12.7 (12.5 to 13.0$)$ & $\begin{array}{r}-10.6(-11.4 \text { to } \\
-9.7)\end{array}$ & $7.9(7.5$ to 8.2$)$ & $\begin{array}{r}-18.1(-19.3 \text { to } \\
-17.0)\end{array}$ \\
\hline Other, non-Hispanic ${ }^{f}$ & $6.9(6.7$ to 7.1$)$ & 4.4 (3.7 to 5.2$)$ & $7.5(7.2$ to 7.7$)$ & $4.6(3.8$ to 5.4$)$ & 3.9 (3.7 to 4.2$)$ & $-2.0(-2.8$ to -1.3$)$ \\
\hline \multicolumn{7}{|l|}{ Education $^{\mathrm{g}}$} \\
\hline$<$ High school graduate & 15.2 (14.9 to 15.5$)$ & $\begin{array}{r}-14.3(-15.4 \text { to } \\
-13.2)\end{array}$ & 14.8 (14.5 to 15.2$)$ & $\begin{array}{r}-11.9(-13.0 \text { to } \\
-10.9)\end{array}$ & $17.2(16.7$ to 17.7$)$ & $\begin{array}{r}-12.3(-13.9 \text { to } \\
-10.8)\end{array}$ \\
\hline High school graduate & 27.9 (27.7 to 28.2$)$ & $-9.0(-10.0$ to -8.0$)$ & 26.3 (26.0 to 26.6 ) & $-6.9(-7.9$ to -5.9$)$ & 36.2 (35.7 to 36.7$)$ & $-4.1(-5.7$ to -2.5$)$ \\
\hline Some college & 29.8 (29.5 to 30.1) & $0.8(-0.2$ to 1.9$)$ & 29.8 (29.5 to 30.2$)$ & $-1.5(-2.5$ to -0.4$)$ & 29.5 (29.0 to 30.0$)$ & 5.5 (3.9 to 7.0$)$ \\
\hline College graduate & 27.1 (26.8 to 27.3$)$ & 22.5 (21.7 to 23.3 ) & 29.1 (28.8 to 29.4$)$ & 20.3 (19.4 to 21.1) & 17.1 (16.8 to 17.5$)$ & 10.9 (9.9 to 11.9$)$ \\
\hline \multicolumn{7}{|c|}{ Annual household income, $\$$} \\
\hline$<25,000$ & $31.0(30.7$ to 31.3$)$ & $\begin{array}{r}-23.3(-24.5 \text { to } \\
-22.2)\end{array}$ & 30.1 (29.7 to 30.5) & $\begin{array}{r}-19.6(-20.8 \text { to } \\
-18.5)\end{array}$ & 35.5 (35.0 to 36.1$)$ & $\begin{array}{r}-21.6(-23.4 \text { to } \\
-19.9)\end{array}$ \\
\hline $25,000-<50,000$ & 25.1 (24.8 to 25.4 ) & $-6.1(-7.2$ to -5.1$)$ & 24.2 (23.9 to 24.6$)$ & $-6.8(-7.8$ to -5.7$)$ & 29.5 (29.0 to 30.1$)$ & 0.1 (-1.6 to 1.8$)$ \\
\hline
\end{tabular}

Abbreviations: -, not applicable; $\mathrm{Cl}$, confidence interval; metro, metropolitan; nonmetro, nonmetropolitan.

a Metropolitan and nonmetropolitan categories were created by using the Office of Management and Budget's February 2013 delineations; US Census Bureau,

Population Division; http://www.census.gov/population/metro/.

${ }^{b}$ County economic status was derived by using 2013 unemployment rate, per capita market income, and poverty rate for each county. An index was used to order counties into quintiles (poorest, poor, middle, affluent, and most affluent).

${ }^{\mathrm{c}}$ Analyses excluded data from respondents in Alaska and Hawaii.

${ }^{d}$ Weighted percentages or percentage points and $95 \% \mathrm{Cl}$.

e Unweighted sample sizes.

${ }^{f}$ Other race includes American Indian, Alaskan Native, Asian, Native Hawaiian, Other Pacific Islander, and multiracial.

${ }^{g}$ Reported for respondents aged 25 years or older.

${ }^{\mathrm{h}}$ Self-reported no leisure-time physical activity within the previous month.

i Self-reported general health as fair or poor.

${ }^{j}$ Self-reported body mass index greater than $25 \mathrm{~kg} / \mathrm{m}^{2}$.

${ }^{\mathrm{k}}$ Self-reported being told they had the condition or disease. By definition, this excludes undiagnosed conditions or diseases.

' Self-reported smoking 100 cigarettes in their lifetimes and currently smoke cigarettes. By definition, this excludes former smokers.

(continued on next page)

The opinions expressed by authors contributing to this journal do not necessarily reflect the opinions of the U.S. Department of Health and Human Services, the Public Health Service, the Centers for Disease Control and Prevention, or the authors' affiliated institutions. 
(continued)

Table 1. Prevalence of Chronic Disease and Risk Factors by County Metropolitan Classification ${ }^{a}$ and Differences Between Most Affluent and Poorest Counties ${ }^{b}$, Adults ( $\geq 18 \mathrm{y}$ ), Behavioral Risk Factor Surveillance System, 2013 ${ }^{\mathrm{C}}$

\begin{tabular}{|c|c|c|c|c|c|c|}
\hline Characteristic & Overall, \% $(95 \% \mathrm{Cl})^{d}$ & $\begin{array}{l}\text { Overall Difference } \\
\text { Between Most } \\
\text { Affluent and } \\
\text { Poorest, Percentage } \\
\text { Points }(95 \% \mathrm{Cl})^{8}\end{array}$ & Metro, \% $(95 \% \mathrm{Cl})^{\mathrm{d}}$ & $\begin{array}{l}\text { Metro Difference } \\
\text { Between Most } \\
\text { Affluent and } \\
\text { Poorest, Percentage } \\
\text { Points (95\% Cl) }\end{array}$ & $\begin{array}{l}\text { Nonmetro, } \\
\text { Cl) }\end{array}$ & $\begin{array}{l}\text { Nonmetro } \\
\text { Difference Between } \\
\text { Most Affluent and } \\
\text { Poorest, Percentage } \\
\text { Points (95\% Cl) }\end{array}$ \\
\hline $50,000-<75,000$ & 14.8 (14.6 to 15.0$)$ & 3.1 (2.3 to 3.9$)$ & 14.6 (14.4 to 14.9$)$ & 2.1 (1.3 to 2.9 ) & 15.8 (15.4 to 16.3$)$ & 6.0 (4.8 to 7.2$)$ \\
\hline$\geq 75,000$ & 29.1 (28.8 to 29.4 ) & 26.4 (25.4 to 27.4$)$ & 31.1 (30.7 to 31.4) & 24.3 (23.2 to 25.3 ) & 19.1 (18.7 to 19.6$)$ & 15.6 (14.1 to 17.0 ) \\
\hline $\begin{array}{l}\text { No leisure-time physical } \\
\text { activity }\end{array}$ & 26.6 (26.3 to 26.8 ) & $-9.4(-10.5$ to -9.4$)$ & 25.7 (25.4 to 26.0 ) & $-6.9(-7.9$ to -5.8$)$ & 31.3 (30.8 to 31.9) & $-8.4(-10.1$ to -6.7$)$ \\
\hline Poor health ${ }^{i}$ & 18.3 (18.1 to 18.6$)$ & $\begin{array}{r}-11.7(-12.6 \text { to } \\
-10.8)\end{array}$ & 17.7 (17.4 to 18.0$)$ & $-9.4(-10.3$ to -8.5$)$ & 21.5 (21.1 to 22.0 ) & $\begin{array}{r}-12.1(-13.5 \text { to } \\
-10.7)\end{array}$ \\
\hline Overweight or obese ${ }^{j}$ & 64.5 (64.2 to 64.8$)$ & $-9.9(-11.0$ to -8.9$)$ & 63.7 (63.3 to 64.0$)$ & $-7.8(-9.0$ to -6.7$)$ & 68.7 (68.1 to 69.2$)$ & $-6.8(-8.5$ to -5.2$)$ \\
\hline Hypertension $^{k}$ & 33.6 (33.3 to 33.8 ) & $-8.7(-9.7$ to -7.6$)$ & 32.6 (32.3 to 33.0) & $-6.2(-7.2$ to -5.1$)$ & 38.1 (37.6 to 38.7) & $\begin{array}{r}-10.1(-11.7 \text { to } \\
-8.5)\end{array}$ \\
\hline High $_{\text {cholesterol }}{ }^{k}$ & 39.4 (39.1 to 39.7) & $-5.0(-6.2$ to -3.8$)$ & 38.8 (38.4 to 39.2$)$ & $-3.5(-4.6$ to -2.3$)$ & 42.4 (41.8 to 43.0$)$ & $-4.8(-6.6$ to -3.1$)$ \\
\hline Heart disease $^{k}$ & $6.9(6.7$ to 7.0$)$ & $-3.0(-3.5$ to -2.5$)$ & $6.5(6.4$ to 6.7$)$ & $-2.4(-2.9$ to -1.9$)$ & $8.6(8.3$ to 8.9$)$ & $-2.8(-3.6$ to -2.0$)$ \\
\hline Arthritis $^{k}$ & 26.1 (25.9 to 26.4 ) & $-7.0(-7.9$ to -6.1$)$ & 25.1 (24.9 to 25.4 ) & $-5.2(-6.1$ to -4.3$)$ & 31.1 (30.6 to 31.6) & $-6.8(-8.3$ to -5.4$)$ \\
\hline Diabetes $^{\mathrm{k}}$ & $10.6(10.5$ to 10.8$)$ & $-4.2(-4.9$ to -3.6$)$ & $10.4(10.2$ to 10.6$)$ & $-3.7(-4.4$ to -3.0$)$ & 12.0 (11.7 to 12.3$)$ & $-5.0(-5.9$ to -4.0$)$ \\
\hline Current cigarette smoker & 18.3 (18.1 to 18.6$)$ & $-7.8(-8.7$ to -6.9$)$ & 17.5 (17.3 to 17.8$)$ & $-5.8(-6.7$ to -4.9$)$ & 22.3 (21.8 to 22.8 ) & $-7.4(-8.8$ to -5.9$)$ \\
\hline Depressive disorder ${ }^{k}$ & 18.0 (17.7 to 18.2$)$ & $-3.5(-4.4$ to -2.7$)$ & 17.5 (17.3 to 17.8$)$ & $-1.7(-2.5$ to -0.9$)$ & 20.1 (19.6 to 20.5) & $-2.9(-4.1$ to -1.6$)$ \\
\hline Asthma $^{\mathrm{k}}$ & 14.0 (13.8 to 14.2$)$ & $-1.7(-2.5$ to -0.9$)$ & 14.0 (13.8 to 14.3$)$ & $-1.6(-2.4$ to -0.8$)$ & 13.9 (13.5 to 14.3$)$ & $-2.4(-3.6$ to -1.3$)$ \\
\hline $\begin{array}{l}\text { Chronic obstructive } \\
\text { pulmonary disease }\end{array}$ & 6.7 (6.6 to 6.8$)$ & $-4.0(-4.5$ to -3.5$)$ & 6.3 (6.2 to 6.5$)$ & $-3.3(-3.8$ to -2.8$)$ & 8.7 (8.4 to 9.0$)$ & $-4.3(-5.2$ to -3.5$)$ \\
\hline
\end{tabular}

Abbreviations: -, not applicable; $\mathrm{Cl}$, confidence interval; metro, metropolitan; nonmetro, nonmetropolitan.

a Metropolitan and nonmetropolitan categories were created by using the Office of Management and Budget's February 2013 delineations; US Census Bureau, Population Division; http://www.census.gov/population/metro/.

${ }^{b}$ County economic status was derived by using 2013 unemployment rate, per capita market income, and poverty rate for each county. An index was used to order counties into quintiles (poorest, poor, middle, affluent, and most affluent).

${ }^{c}$ Analyses excluded data from respondents in Alaska and Hawaii.

${ }^{d}$ Weighted percentages or percentage points and $95 \% \mathrm{Cl}$.

e Unweighted sample sizes.

${ }^{f}$ Other race includes American Indian, Alaskan Native, Asian, Native Hawaiian, Other Pacific Islander, and multiracial.

${ }^{g}$ Reported for respondents aged 25 years or older.

${ }^{\mathrm{h}}$ Self-reported no leisure-time physical activity within the previous month.

'Self-reported general health as fair or poor.

j Self-reported body mass index greater than $25 \mathrm{~kg} / \mathrm{m}^{2}$.

${ }^{\mathrm{k}}$ Self-reported being told they had the condition or disease. By definition, this excludes undiagnosed conditions or diseases.

' Self-reported smoking 100 cigarettes in their lifetimes and currently smoke cigarettes. By definition, this excludes former smokers. 
Table 2. Prevalence of Hypertension, Arthritis, and Poor Health by County Economic Status ${ }^{\mathrm{a}}$ and Metropolitan Classification ${ }^{\mathrm{b}}$ : Demographic Characteristics and Risk Factors of Adults Aged 18 Years or Older, Behavioral Risk Factor Surveillance System, $2013^{\mathrm{c}}$

\begin{tabular}{|c|c|c|c|}
\hline Characteristic & Hypertension $^{d}, \%(95 \% \mathrm{Cl})^{e}$ & Arthritis $^{f}, \%(95 \% \mathrm{Cl})^{\mathrm{e}}$ & Poor Health ${ }^{\mathrm{g}}, \%(95 \% \mathrm{Cl})^{\mathrm{e}}$ \\
\hline \multicolumn{4}{|l|}{ County of residence } \\
\hline Poorest & $38.6(37.7-39.4)$ & $29.7(28.9-30.5)$ & $25.5(24.7-26.4)$ \\
\hline Poor & $37.0(36.4-37.7)$ & $30.0(29.4-30.6)$ & $21.8(21.2-22.4)$ \\
\hline Median & $34.1(33.4-34.7)$ & $26.4(25.9-27.0)$ & $19.3(18.8-19.8)$ \\
\hline Affluent & $32.5(31.9-33.0)$ & $25.4(24.9-25.9)$ & $16.7(16.2-17.2)$ \\
\hline Most affluent & $29.9(29.4-30.4)$ & $22.7(22.3-23.2)$ & $13.9(13.5-14.3)$ \\
\hline \multicolumn{4}{|l|}{ County metropolitan } \\
\hline Metropolitan & $32.6(32.3-33.0)$ & $25.1(24.9-25.4)$ & $17.7(17.4-18.0)$ \\
\hline Nonmetropolitan & $38.1(37.6-38.7)$ & $31.1(30.6-31.6)$ & $21.5(21.1-22.0)$ \\
\hline \multicolumn{4}{|l|}{ Age, y } \\
\hline $18-44$ & $14.3(13.9-14.6)$ & $8.9(8.6-9.2)$ & $12.2(11.9-12.6)$ \\
\hline $45-64$ & $41.3(40.8-41.8)$ & $33.1(32.6-33.5)$ & $21.9(21.5-22.3)$ \\
\hline$\geq 65$ & $63.2(62.7-63.7)$ & $53.0(52.4-53.5)$ & $25.9(25.4-26.4)$ \\
\hline \multicolumn{4}{|l|}{ Sex } \\
\hline Male & $35.1(34.7-35.6)$ & $22.0(21.7-22.4)$ & $17.4(17.1-17.8)$ \\
\hline Female & $32.1(31.7-32.5)$ & $29.9(29.6-30.3)$ & $19.1(18.8-19.5)$ \\
\hline \multicolumn{4}{|l|}{ Race/ethnicity } \\
\hline Hispanic & $24.8(23.9-25.8)$ & $14.4(13.7-15.1)$ & $26.0(25.1-27.0)$ \\
\hline White, non-Hispanic & $34.6(34.3-34.9)$ & $29.6(29.4-29.9)$ & $15.9(15.7-16.2)$ \\
\hline Black, non-Hispanic & $42.8(41.8-43.8)$ & $25.8(25.0-26.6)$ & $23.1(22.3-23.9)$ \\
\hline Other, non-Hispanic ${ }^{h}$ & $27.2(25.8-28.7)$ & $19.3(18.1-20.5)$ & $15.5(14.4-16.6)$ \\
\hline \multicolumn{4}{|l|}{ Education ${ }^{i}$} \\
\hline$<$ High school graduate & $43.6(42.5-44.6)$ & $34.2(33.2-35.2)$ & $41.6(40.5-42.6)$ \\
\hline High school graduate & $41.5(40.9-42.0)$ & $32.9(32.4-33.4)$ & $22.3(21.9-22.8)$ \\
\hline Some college & $37.4(36.9-38.0)$ & $30.6(30.1-31.1)$ & $16.9(16.4-17.3)$ \\
\hline College graduate & $28.9(28.5-29.4)$ & $21.6(21.3-22.0)$ & $7.9(7.6-8.1)$ \\
\hline
\end{tabular}

Abbreviation: $\mathrm{Cl}$, confidence interval.

${ }^{a}$ County economic status was determined by using 2013 unemployment rate, per capita market income, and poverty rate for each county. An index was used to order counties into quintiles (poorest, poor, median, affluent, and most affluent).

${ }^{b}$ Metropolitan and nonmetropolitan categories were created by using the Office of Management and Budget's February 2013 delineations; US Census Bureau,

Population Division; http://www.census.gov/population/metro/.

${ }^{c}$ Analyses excluded data from respondents in Alaska and Hawaii.

${ }^{d}$ Self-reported being told by a health professional that they had high blood pressure.

e Weighted percentage and 95\% confidence interval.

${ }^{f}$ Self-reported being told by a health professional that they had some form of arthritis, rheumatoid arthritis, gout, lupus, or fibromyalgia.

${ }^{g}$ Self-reported general health as poor or fair.

${ }^{\mathrm{h}}$ Other race includes American Indian, Alaskan Native, Asian, Native Hawaiian, Other Pacific Islander, and multiracial.

${ }^{i}$ Reported for respondents aged 25 years or older.

${ }^{j}$ Reported having health insurance at the time of the survey.

${ }^{\mathrm{k}}$ Self-reported height and weight equivalent to body mass index greater than $25 \mathrm{~kg} / \mathrm{m}^{2}$.

' Self-reported smoking 100 cigarettes and currently smoke cigarettes. By definition, this excludes former cigarette smokers.

${ }^{\mathrm{m}}$ Self-reported leisure-time physical activity within the previous month.

(continued on next page)

The opinions expressed by authors contributing to this journal do not necessarily reflect the opinions of the U.S. Department of Health and Human Services, the Public Health Service, the Centers for Disease Control and Prevention, or the authors' affiliated institutions. 
(continued)

Table 2. Prevalence of Hypertension, Arthritis, and Poor Health by County Economic Status ${ }^{a}$ and Metropolitan Classification ${ }^{\mathrm{b}}$ : Demographic Characteristics and Risk Factors of Adults Aged 18 Years or Older, Behavioral Risk Factor Surveillance System, $2013^{\mathrm{c}}$

\begin{tabular}{|c|c|c|c|}
\hline Characteristic & Hypertension $^{\mathrm{d}}$, \% $(95 \% \mathrm{Cl})^{\mathrm{e}}$ & Arthritis ${ }^{\mathrm{f}}, \%(95 \% \mathrm{Cl})^{\mathrm{e}}$ & Poor Health ${ }^{\mathrm{g}}, \%(95 \% \mathrm{Cl})^{\mathrm{e}}$ \\
\hline$<25,000$ & $38.6(38.0-39.2)$ & $31.6(31.1-32.2)$ & $33.4(32.8-34.0)$ \\
\hline $25,000-<50,000$ & $35.8(35.2-36.4)$ & $27.5(27.0-28.1)$ & $17.5(17.0-18.1)$ \\
\hline $50,000-75,000$ & $32.5(31.8-33.2)$ & $24.7(24.0-25.3)$ & $10.4(9.9-10.9)$ \\
\hline$\geq 75,000$ & $26.8(26.3-27.3)$ & $19.3(18.9-19.7)$ & $5.9(5.7-6.2)$ \\
\hline \multicolumn{4}{|l|}{\begin{tabular}{|l|} 
Health insurance \\
\end{tabular}} \\
\hline Yes & $35.7(35.4-36.0)$ & $28.4(28.2-28.7)$ & $17.3(17.0-17.5)$ \\
\hline No & $23.7(23.0-24.4)$ & $15.3(14.8-15.9)$ & $23.6(22.9-24.3)$ \\
\hline \multicolumn{4}{|c|}{ Overweight or obese $^{k}$} \\
\hline Yes & $41.0(40.7-41.4)$ & $30.1(29.8-30.4)$ & $20.9(20.6-21.2)$ \\
\hline No & $20.6(20.2-21.0)$ & $19.6(19.3-20.0)$ & $13.7(13.3-14.1)$ \\
\hline \multicolumn{4}{|c|}{ Current cigarette smoker } \\
\hline Yes & $32.8(32.2-33.5)$ & $28.7(28.1-29.3)$ & $26.8(26.1-27.4)$ \\
\hline No & $33.9(33.5-34.2)$ & $25.8(25.5-26.1)$ & $16.4(16.1-16.6)$ \\
\hline \multicolumn{4}{|l|}{ Physical activity $^{\mathrm{m}}$} \\
\hline Yes & $30.8(30.5-31.2)$ & $23.7(23.4-24.0)$ & $13.7(13.4-13.9)$ \\
\hline No & $42.1(41.5-42.7)$ & $34.5(34.0-35.1)$ & $30.7(30.2-31.3)$ \\
\hline
\end{tabular}

Abbreviation: $\mathrm{Cl}$, confidence interval.

${ }^{a}$ County economic status was determined by using 2013 unemployment rate, per capita market income, and poverty rate for each county. An index was used to order counties into quintiles (poorest, poor, median, affluent, and most affluent).

${ }^{b}$ Metropolitan and nonmetropolitan categories were created by using the Office of Management and Budget's February 2013 delineations; US Census Bureau,

Population Division; http://www.census.gov/population/metro/.

${ }^{\mathrm{C}}$ Analyses excluded data from respondents in Alaska and Hawaii.

${ }^{d}$ Self-reported being told by a health professional that they had high blood pressure.

e Weighted percentage and 95\% confidence interval.

${ }^{f}$ Self-reported being told by a health professional that they had some form of arthritis, rheumatoid arthritis, gout, lupus, or fibromyalgia.

${ }^{g}$ Self-reported general health as poor or fair.

${ }^{\mathrm{h}}$ Other race includes American Indian, Alaskan Native, Asian, Native Hawaiian, Other Pacific Islander, and multiracial.

i Reported for respondents aged 25 years or older.

${ }^{\mathrm{j}}$ Reported having health insurance at the time of the survey.

${ }^{\mathrm{k}}$ Self-reported height and weight equivalent to body mass index greater than $25 \mathrm{~kg} / \mathrm{m}^{2}$

' Self-reported smoking 100 cigarettes and currently smoke cigarettes. By definition, this excludes former cigarette smokers.

${ }^{\mathrm{m}}$ Self-reported leisure-time physical activity within the previous month. 
Table 3. Adjusted Prevalence Ratios of Hypertension, Arthritis, and Poor Health, Adults Aged 18 Years or Older, Behavioral Risk Factor Surveillance System, $2013^{a}$

\begin{tabular}{|c|c|c|c|}
\hline Characteristic & Hypertension $^{\mathrm{b}}$, APR $(95 \% \mathrm{Cl})^{\mathrm{e}}$ & Arthritis $^{c}$, APR $(95 \% \mathrm{Cl})^{\mathrm{e}}$ & Poor Health ${ }^{d}$, APR $(95 \% \mathrm{Cl})^{\mathrm{e}}$ \\
\hline \multicolumn{4}{|l|}{ County of residence $^{f}$} \\
\hline Poorest & $1.09(1.05-1.12)$ & $1.13(1.09-1.18)$ & $1.15(1.10-1.21)$ \\
\hline Poor & $1.06(1.04-1.09)$ & $1.11(1.08-1.14)$ & $1.10(1.05-1.14)$ \\
\hline Median & $1.04(1.02-1.07)$ & $1.06(1.03-1.09)$ & $1.07(1.02-1.12)$ \\
\hline Affluent & $1.03(1.01-1.06)$ & $1.06(1.03-1.08)$ & $1.03(0.99-1.07)$ \\
\hline Most affluent & & & 1 [Reference] \\
\hline \multicolumn{4}{|l|}{ County metropolitan ${ }^{g}$} \\
\hline Metropolitan & & & 1 [Reference] \\
\hline Nonmetropolitan & $1.03(1.01-1.04)$ & $0.99(0.97-1.02)$ & $0.99(0.96-1.02)$ \\
\hline \multicolumn{4}{|l|}{ Age, $y$} \\
\hline $18-44$ & & & 1 [Reference] \\
\hline $45-64$ & $2.23(2.16-2.30)$ & $2.65(2.56-2.75)$ & $1.67(1.60-1.74)$ \\
\hline$\geq 65$ & $3.36(3.26-3.47)$ & $3.87(3.73-4.02)$ & $1.72(1.64-1.80)$ \\
\hline \multicolumn{4}{|l|}{ Sex } \\
\hline Male & & & 1 [Reference] \\
\hline Female & $0.90(0.88-0.91)$ & $1.28(1.25-1.30)$ & $1.02(0.99-1.05)$ \\
\hline \multicolumn{4}{|l|}{ Race/ethnicity } \\
\hline Hispanic & $0.90(0.86-0.93)$ & $0.63(0.60-0.67)$ & $1.24(1.18-1.30)$ \\
\hline White, non-Hispanic & & & 1 [Reference] \\
\hline Black, non-Hispanic & $1.28(1.24-1.31)$ & $0.86(0.83-0.89)$ & $1.09(1.04-1.14)$ \\
\hline Other, non-Hispanic ${ }^{\text {h }}$ & $1.09(1.04-1.14)$ & $0.93(0.88-0.98)$ & $1.16(1.07-1.25)$ \\
\hline \multicolumn{4}{|l|}{ Education $^{i}$} \\
\hline$<$ High school graduate & $1.14(1.10-1.18)$ & $1.23(1.18-1.28)$ & $1.91(1.81-2.02)$ \\
\hline High school graduate & $1.10(1.07-1.12)$ & $1.11(1.08-1.13)$ & $1.33(1.27-1.39)$ \\
\hline Some college & $1.10(1.08-1.12)$ & $1.17(1.14-1.20)$ & $1.29(1.23-1.35)$ \\
\hline College graduate & & & 1 [Reference] \\
\hline \multicolumn{4}{|c|}{ Annual household income, $\$$} \\
\hline$<25,000$ & $1.32(1.29-1.36)$ & $1.55(1.50-1.60)$ & $3.63(3.41-3.86)$ \\
\hline
\end{tabular}

Abbreviations: APR, adjusted prevalence ratio; $\mathrm{Cl}$, confidence interval.

${ }^{a}$ Analyses excluded data from respondents in Alaska and Hawaii.

${ }^{b}$ Self-reported ever being told by a health professional that they had high blood pressure.

${ }^{\mathrm{c}}$ Self-reported ever being told by a health professional that they had some form of arthritis, rheumatoid arthritis, gout, lupus, or fibromyalgia.

${ }^{\mathrm{d}}$ Self-reported general health as poor or fair.

${ }^{\text {e }}$ Adjusted prevalence ratio and 95\% confidence interval; multivariable logistic regression model included all variables in the table.

${ }^{f}$ County economic status was created by using 2013 unemployment rate, per capita market income, and poverty rate for each county. An index was used to order counties into quintiles (poorest, poor, median, affluent, and most affluent).

${ }^{\mathrm{g}}$ Metropolitan and nonmetropolitan categories were created by using the Office of Management and Budget's February 2013 delineations; US Census Bureau,

Population Division; http://www.census.gov/population/metro/.

${ }^{\mathrm{h}}$ Other race includes American Indian, Alaskan Native, Asian, Native Hawaiian, Other Pacific Islander, and multiracial.

${ }^{i}$ Reported for respondents aged 25 years or older.

${ }^{j}$ Reported having health insurance at the time of the survey.

${ }^{\mathrm{k}}$ Self-reported height and weight equivalent to body mass index greater than $25 \mathrm{~kg} / \mathrm{m}^{2}$.

' Self-reported smoking 100 cigarettes and currently smokes cigarettes. By definition, this excludes former smokers.

${ }^{\mathrm{m}}$ Self-reported leisure-time physical activity within the previous month.

(continued on next page)

The opinions expressed by authors contributing to this journal do not necessarily reflect the opinions of the U.S. Department of Health and Human Services, the Public Health Service, the Centers for Disease Control and Prevention, or the authors' affiliated institutions. 
(continued)

Table 3. Adjusted Prevalence Ratios of Hypertension, Arthritis, and Poor Health, Adults Aged 18 Years or Older, Behavioral Risk Factor Surveillance System, 2013 ${ }^{a}$

\begin{tabular}{|c|c|c|c|}
\hline Characteristic & Hypertension $^{\mathrm{b}}, \mathrm{APR}(95 \% \mathrm{Cl})^{\mathrm{e}}$ & Arthritis $^{\mathrm{c}}$, APR $(95 \% \mathrm{Cl})^{\mathrm{e}}$ & Poor Health ${ }^{d}$, APR $\left(95 \%\right.$ Cl) ${ }^{e}$ \\
\hline $25,000-<50,000$ & $1.15(1.12-1.18)$ & $1.24(1.20-1.28)$ & $2.10(1.97-2.23)$ \\
\hline $50,000-<75,000$ & $1.09(1.06-1.12)$ & $1.13(1.10-1.17)$ & $1.43(1.33-1.53)$ \\
\hline$\geq 75,000$ & & & 1 [Reference] \\
\hline \multicolumn{4}{|l|}{ Health insurance } \\
\hline Yes & & & 1 [Reference] \\
\hline No & $0.84(0.82-0.87)$ & $0.73(0.70-0.76)$ & $0.86(0.83-0.91)$ \\
\hline \multicolumn{4}{|c|}{ Overweight or obese ${ }^{k}$} \\
\hline Yes & $1.68(1.64-1.72)$ & $1.37(1.34-1.41)$ & $1.28(1.23-1.32)$ \\
\hline No & & & 1 [Reference] \\
\hline \multicolumn{4}{|c|}{ Current cigarette smoker' } \\
\hline Yes & $1.05(1.02-1.07)$ & $1.19(1.16-1.22)$ & $1.31(1.27-1.35)$ \\
\hline No & & & 1 [Reference] \\
\hline \multicolumn{4}{|l|}{ Physical activity ${ }^{\mathrm{m}}$} \\
\hline Yes & & & 1 [Reference] \\
\hline No & $1.11(1.09-1.14)$ & $1.15(1.13-1.18)$ & $1.58(1.54-1.63)$ \\
\hline
\end{tabular}

Abbreviations: APR, adjusted prevalence ratio; $\mathrm{Cl}$, confidence interval.

${ }^{a}$ Analyses excluded data from respondents in Alaska and Hawaii.

${ }^{b}$ Self-reported ever being told by a health professional that they had high blood pressure.

${ }^{c}$ Self-reported ever being told by a health professional that they had some form of arthritis, rheumatoid arthritis, gout, lupus, or fibromyalgia.

${ }^{\mathrm{d}}$ Self-reported general health as poor or fair.

${ }^{\mathrm{e}}$ Adjusted prevalence ratio and $95 \%$ confidence interval; multivariable logistic regression model included all variables in the table.

${ }^{f}$ County economic status was created by using 2013 unemployment rate, per capita market income, and poverty rate for each county. An index was used to order counties into quintiles (poorest, poor, median, affluent, and most affluent).

${ }^{g}$ Metropolitan and nonmetropolitan categories were created by using the Office of Management and Budget's February 2013 delineations; US Census Bureau,

Population Division; http://www.census.gov/population/metro/.

${ }^{\mathrm{h}}$ Other race includes American Indian, Alaskan Native, Asian, Native Hawaiian, Other Pacific Islander, and multiracial.

i Reported for respondents aged 25 years or older.

${ }^{\mathrm{j}}$ Reported having health insurance at the time of the survey.

${ }^{\mathrm{k}}$ Self-reported height and weight equivalent to body mass index greater than $25 \mathrm{~kg} / \mathrm{m}^{2}$.

' Self-reported smoking 100 cigarettes and currently smokes cigarettes. By definition, this excludes former smokers.

${ }^{\mathrm{m}}$ Self-reported leisure-time physical activity within the previous month. 